\title{
Infectious Complications Following Snakebite by Bothrops lanceolatus in Martinique: A Case Series
}

\author{
Dabor Resiere, ${ }^{1 \star}$ Hossein Mehdaoui, ${ }^{1}$ Rémi Névière,${ }^{2}$ Claude Olive, ${ }^{3}$ Mathieu Severyns, ${ }^{4}$ Adeline Beaudoin, ${ }^{1}$ Jonathan Florentin, ${ }^{1}$ \\ Yannick Brouste, ${ }^{1}$ Rishika Banydeen, ${ }^{1}$ André Cabié, ${ }^{5}$ Bruno Mégarbane, ${ }^{6}$ José María Gutiérrez, ${ }^{7}$ and Hatem Kallel ${ }^{8}$ \\ ${ }^{1}$ Department of Critical Care, University Hospital of Martinique, Fort-de-France, France; ${ }^{2}$ Department of Cardiology, University Hospital of \\ Martinique, Fort-de-France, France; ${ }^{3}$ Department of Microbiology, University Hospital of Martinique, Fort-de-France, France; ${ }^{4}$ Department \\ of Orthopedic Surgery, University Hospital of Martinique, Fort-de-France, France; ${ }^{5}$ Department of Infectious Diseases, University Hospital of \\ Martinique, INSERM CIC 1424, Antilles University, Fort-de-France, France; ${ }^{6}$ Department of Medical and Toxicological Critical Care, Lariboisière \\ Hospital, Paris-Diderot University, INSERM UMRS1144, Paris, France; ${ }^{7}$ Instituto Clodomiro Picado, Facultad de Microbiología, Universidad de \\ Costa Rica, San José, Costa Rica; ${ }^{8}$ Intensive Care Unit, Cayenne General Hospital, Cayenne, France
}

\begin{abstract}
Infections secondary to snakebite occur in a number of patients and are potentially life-threatening. Bothrops lanceolatus bites in Martinique average 30 cases per year and may result in severe thrombotic and infectious complications. We aimed to investigate the infectious complications related to $B$. lanceolatus bite. A retrospective singlecenter observational study over 7 years (2011-2018) was carried out, including all patients admitted to the hospital because of $B$. lanceolatus bite. One hundred seventy snake-bitten patients (121 males and 49 females) were included. Thirty-nine patients (23\%) presented grade 3 or 4 envenoming. Twenty patients $(12 \%)$ developed wound infections. The isolated bacteria were Aeromonas hydrophila (3 cases), Morganella morganii (two cases), group A Streptococcus, and group B Streptococcus (one case each). Patients were treated empirically with third-generation cephalosporin (or amoxicillin-clavulanate), aminoglycoside, and metronidazole combinations. Outcome was favorable in all patients. The main factor significantly associated with the occurrence of infection following snakebite was the severity of envenoming $(P<0.05)$. Our findings clearly point toward the frequent onset of infectious complications in $B$. lanceolatus-bitten patients presenting with grade 3 and 4 envenoming. Thus, based on the bacteria identified in the wounds, we suggest that empiric antibiotic therapy including third-generation cephalosporin should be administered to those patients on hospital admission.
\end{abstract}

\section{INTRODUCTION}

Snakebites account for about 1.8-2.7 million envenomings and $81,000-138,000$ deaths per year worldwide. ${ }^{1}$ In Martinique, about 30 cases of snakebite are recorded every year. Bothrops lanceolatus, a member of the Viperidae family, Crotalinae subfamily, is the only venomous species encountered in Martinique. ${ }^{2}$ Bothrops lanceolatus bite may result in severe thrombotic complications, including cerebral, pulmonary, and myocardial infarction, as well as coagulation disorders and endothelial injuries, which could be fatal or involve long-term sequelae. ${ }^{2-4}$ Thus, envenomed patients should promptly receive a specific antivenom to prevent such severe complications.

Snakebites are frequently responsible for local complications combining pain and local edema in the minutes following the bite, followed, in severe cases, by local necrosis and blistering. Wound infection may contribute to tissue necrosis, bacteremia, and even septic shock. ${ }^{5,6}$ Like in envenomings by other snakes, such infectious complications are routinely observed following $B$. lanceolatus bite, but their precise incidence is unknown.

The oral bacterial flora of $B$. lanceolatus includes Aeromonas hydrophila, Morganella morganii, Klebsiella pneumoniae, Bacillus spp., and Enterococcus spp. ${ }^{7}$ These bacteria are usually found in post-snakebite abscesses, suggesting that they have been inoculated in the wound from the snake oral cavity, thus supporting the possible need for empiric antibiotic treatment after the snakebite, particularly in cases associated with prominent local tissue damage. Interestingly, local effects of the venom, such as tissue necrosis, edema, and vascular damage, constitute a favorable environment for bacterial growth.

* Address correspondence to Dabor Resiere, Department of Critical Care, University Hospital of Martinique, CS 90632, Fort-de-France F-9720061, France. E-mail: dabor.resiere@chu-martinique.fr
Because data regarding the risk and outcome of infectious complications resulting from $B$. lanceolatus bite are poorly known, we designed this observational study to determine the incidence of wound infection in patients bitten by this species and describe the involved bacteria and the patients' outcome.

\section{PATIENTS AND METHODS}

We conducted a retrospective single-center observational study at the University Hospital of Martinique from January 1, 2011 to September 4, 2018. In Martinique, all B. lanceolatus-bitten patients

TABLE 1

Severity score of envenoming after Bothrops lanceolatus bite (adapted from ref. 11)

\begin{tabular}{|c|c|c|}
\hline Grade & Severity & Symptoms \\
\hline$\overline{1}$ & Minor & $\begin{array}{l}\text { No swelling } \\
\text { No pain } \\
\text { No general signs }\end{array}$ \\
\hline 2 & Moderate & $\begin{array}{l}\text { Local swelling confined to two segments } \\
\text { of the bitten limb } \\
\text { Moderate pain } \\
\text { No general signs }\end{array}$ \\
\hline 3 & Severe & $\begin{array}{l}\text { Regional edema, extension of swelling } \\
\text { beyond two segments of the bitten limb } \\
\text { Persistent and resistant pain to } \\
\text { analgesics } \\
\text { No general signs }\end{array}$ \\
\hline 4 & Major & $\begin{array}{l}\text { Swelling spreading to the trunk } \\
\text { General signs (vomiting, headache, and } \\
\text { abdominal or chest pain) } \\
\text { Hypotension } \\
\text { Isolated thrombocytopenia } \\
\text { Disseminated intravascular coagulation }\end{array}$ \\
\hline
\end{tabular}

Severity is defined by at least one confirmed item. 
are referred to our hospital because the BothroFav ${ }^{\circledR}$ antivenom is only available at our Emergency Department.

All patients admitted to the hospital for snakebite by $B$. lanceolatus during the study period were included. Patients with a history of snakebite but without medical or computer records and patients with a history of bite but without evidence of envenoming were excluded. Our database has been registered at the Commission Nationale de l'Informatique et des
Libertés (registration $n^{\circ} 2213908$ v 0.) in compliance with the French law on electronic data sources.

Data collection. Patients were selected using the medical information department database, the antivenom dispensing list, and the emergency department records. Clinical and biological data were collected from the patient medical records and the various emergency department software (Dx Care, $\mathrm{X}$-plore, and cyberlab). We collected the usual demographic,

TABLE 2

Clinical parameters recorded in 170 Bothrops lanceolatus-bitten patients on hospital admission

\begin{tabular}{|c|c|c|c|c|}
\hline Variables & Total patients $(N=170)$ & Infected patients $(N=20)$ & Noninfected patients $(N=150)$ & $P$-value \\
\hline Age (years) & $45 \pm 18$ & $48 \pm 15$ & $45 \pm 18$ & 0.4 \\
\hline Male, $N(\%)$ & $121(71 \%)$ & $15(75 \%)$ & $106(71 \%)$ & 0.7 \\
\hline Hospitalization, $N(\%)$ & $107(63 \%)$ & $20(100 \%)$ & $87(58 \%)$ & $<0.0001$ \\
\hline \multicolumn{5}{|l|}{ Past medical history } \\
\hline Snakebite, $N(\%)$ & $10(6 \%)$ & $1(5 \%)$ & $9(6 \%)$ & 0.9 \\
\hline Immunosuppression, $N(\%)$ & $4(2 \%)$ & $2(10 \%)$ & $2(1 \%)$ & 0.02 \\
\hline Cardiovascular risk, $N(\%)$ & $28(17 \%)$ & $3(15 \%)$ & $25(17 \%)$ & 0.9 \\
\hline Coagulopathy, $N(\%)$ & $4(2 \%)$ & $2(10 \%)$ & $2(1 \%)$ & 0.02 \\
\hline \multicolumn{5}{|l|}{ Snakebite characteristics } \\
\hline $\begin{array}{l}\text { Time from envenoming to admission } \\
\text { (hours) }\end{array}$ & $3.5 \pm 4.3$ & $3.7 \pm 4.7$ & $3.5 \pm 4.3$ & 0.8 \\
\hline Snake captured, $N(\%)$ & $45(27 \%)$ & $8(40 \%)$ & $37(25 \%)$ & 0.1 \\
\hline Site of the bite, $N(\%)$ & & & & 0.8 \\
\hline Upper limb & $71(42 \%)$ & $10(50 \%)$ & $61(41 \%)$ & \\
\hline Lower limb & 98 (58\%) & $10(50 \%)$ & 88 (59\%) & \\
\hline Buttock & $1(1 \%)$ & 0 & $1(1 \%)$ & \\
\hline Local bleeding, $N(\%)$ & $91(54 \%)$ & $11(55 \%)$ & $80(53 \%)$ & 0.9 \\
\hline Local pain, $N(\%)$ & $163(96 \%)$ & $19(95 \%)$ & $144(96 \%)$ & 0.833 \\
\hline \multicolumn{5}{|l|}{ Envenoming grade, $N(\%)$} \\
\hline 1 & $22(13 \%)$ & 0 & $22(15 \%)$ & - \\
\hline 2 & $109(64 \%)$ & $8(40 \%)$ & $101(67 \%)$ & - \\
\hline 3 & $33(19 \%)$ & $8(40 \%)$ & $25(17 \%)$ & - \\
\hline 4 & $6(4 \%)$ & $4(20 \%)$ & $2(1 \%)$ & - \\
\hline \multicolumn{5}{|l|}{ Clinical presentation and complications } \\
\hline Heart rate (beat/min) & $80 \pm 16$ & $79 \pm 16$ & $80 \pm 16$ & 0.9 \\
\hline Temperature $\left({ }^{\circ} \mathrm{C}\right)$ & $36.8 \pm 0.8$ & $37.1 \pm 0.7$ & $36.8 \pm 0.5$ & 0.7 \\
\hline Systolic arterial pressure $(\mathrm{mmHg})$ & $137 \pm 24$ & $128 \pm 27$ & $139 \pm 23$ & 0.04 \\
\hline Diastolic arterial pressure $(\mathrm{mmHg})$ & $80 \pm 15$ & $75 \pm 14$ & $81 \pm 15$ & 0.1 \\
\hline Mean arterial pressure $(\mathrm{mmHg})$ & $99 \pm 16$ & $93 \pm 17$ & $100 \pm 16$ & 0.05 \\
\hline $\mathrm{SpO}_{2}(\%)$ & $99 \pm 2$ & $99 \pm 1$ & $98 \pm 2$ & 0.07 \\
\hline Shock, $N(\%)$ & $3(1.8 \%)$ & $3(15 \%)$ & 0 & - \\
\hline Consciousness impairment, $N(\%)$ & $3(1.8 \%)$ & $3(15 \%)$ & 0 & - \\
\hline Convulsion, $N(\%)$ & $1(0.6 \%)$ & $1(5 \%)$ & 0 & - \\
\hline Thrombosis, $N(\%)$ & $1(1 \%)$ & 0 & $1(1 \%)$ & - \\
\hline Compartmental syndrome, $N(\%)$ & $6(4 \%)$ & $5(25 \%)$ & $1(1 \%)$ & - \\
\hline Bacteremia, $N(\%)$ & $3(2 \%)$ & $3(15 \%)$ & 0 & - \\
\hline \multicolumn{5}{|l|}{ Laboratory parameters on admission } \\
\hline Creatine kinase (IU/L) & $300 \pm 283$ & $311 \pm 257$ & $298 \pm 287$ & 0.9 \\
\hline Platelet count (G/L) & $238 \pm 67$ & $213 \pm 76$ & $241 \pm 65$ & 0.07 \\
\hline Prothrombin index (\%) & $96 \pm 13$ & $92 \pm 17$ & $97 \pm 12$ & 0.09 \\
\hline $\begin{array}{l}\text { Activated partial thromboplastin time } \\
\text { (minutes) }\end{array}$ & $31.5 \pm 3.7$ & $30.6 \pm 3.6$ & $31.6 \pm 3.7$ & 0.3 \\
\hline Fibrinogen (g/L) & $3.0 \pm 0.7$ & $2.9 \pm 1.0$ & $3.0 \pm 0.6$ & 0.7 \\
\hline C-reactive protein (mg/L) & $7 \pm 42$ & $31 \pm 118$ & $4 \pm 7$ & 0.009 \\
\hline White blood cells (G/L) & $7.8 \pm 2.7$ & $9.3 \pm 3.6$ & $7.6 \pm 2.4$ & 0.005 \\
\hline \multicolumn{5}{|l|}{ Antivenom management } \\
\hline Antivenom administration, $N(\%)$ & $154(91 \%)$ & $19(95 \%)$ & $135(90 \%)$ & 0.5 \\
\hline Number of vials & $1.7 \pm 1.3$ & $2.4 \pm 1.5$ & $1.6 \pm 1.3$ & 0.016 \\
\hline $\begin{array}{l}\text { Time from snakebite to antivenom } \\
\text { administration (hour) }\end{array}$ & $6.0 \pm 7.0$ & $6.5 \pm 8.9$ & $5.9 \pm 6.8$ & 0.8 \\
\hline $\begin{array}{l}\text { Time from admission to antivenom } \\
\text { administration (hour) }\end{array}$ & $3.2 \pm 5.3$ & $4.3 \pm 7.5$ & $3.1 \pm 5.0$ & 0.4 \\
\hline Antivenom reinjection, $N(\%)$ & $19(12 \%)$ & $10(53 \%)$ & $9(7 \%)$ & $<0.001$ \\
\hline Empiric antibiotic administration, $N(\%)$ & $37(22 \%)$ & $17(85 \%)$ & $20(13 \%)$ & - \\
\hline Amoxicillin-clavulanate, $N(\%)$ & $11(6 \%)$ & $2(10 \%)$ & $9(6 \%)$ & - \\
\hline Third-generation cephalosporin, $N(\%)$ & $17(10 \%)$ & $6(30 \%)$ & $11(7 \%)$ & - \\
\hline Gentamycin, $N(\%)$ & $12(7 \%)$ & $4(20 \%)$ & $8(5 \%)$ & - \\
\hline Metronidazole, $N(\%)$ & $12(7 \%)$ & $5(25 \%)$ & $7(5 \%)$ & - \\
\hline
\end{tabular}


clinical, biological, microbiological, management, and outcome data. The signs suggestive of $B$. lanceolatus bite, the date of bite onset, the bite zone, and the time between the bite and antivenom administration (if administered) were sought. Monthly rainfall and maximal temperatures recorded in Martinique were obtained from the French national meteorological service (Météo France).

Diagnosis and management of snakebite wound infection. Wound infection following snakebite was defined as the presence of at least two local suggestive signs or as the presence of fever and/or chills and one local suggestive sign. Fever was defined as body temperature above $38^{\circ} \mathrm{C}$ measured using tympanic thermometer. Local signs suggestive of wound infection included pain, erythema, local warmth, swelling, lymphangitis, purulence, delayed healing, crepitus in soft tissues, discolored or friable granulation tissue, and wound breakdown or dehiscence, as previously listed. ${ }^{8,9}$ Because our study was retrospective, if no abnormality was mentioned in the patient record, it was assumed that no infectious complication had resulted from the snakebite.

In patients with local signs of infection, samples obtained from blood cultures, local sampling in case of purulence, and wound culture if patients had surgical debridement were sent to the bacteriology laboratory to identify the involved bacteria. Samples were subjected to Gram staining and examined for bacterial growth. They were plated on nonselective blood agar and chocolate agar and cultured at $37^{\circ} \mathrm{C}$ for $2-7$ days, and the color and shape of the colonies were observed. Species identification was performed with API-20E and API-20NE systems (BioMérieux, Marcy L'Etoile, France). Antimicrobial susceptibilities of all isolates were determined by the disk diffusion method based on the definition of the Antibiogram Committee of the French Microbiology Society. ${ }^{10}$ The inhibition zone diameter of each drug for each isolate was determined after overnight incubation at $35.8^{\circ} \mathrm{C}$ in ambient air. The interpretative criteria of the inhibition zone and minimum inhibitory concentrations were in accordance with those of the Antibiogram Committee of the French Society of Microbiology. ${ }^{10}$ Bacteremia caused by coagulase-negative staphylococci or Bacteroides sp. was defined as two positive results of two independent blood cultures of samples obtained from two distinct peripheral veins.

Severity of the snakebite was graded as previously reported (Table 1). ${ }^{11}$ The snakebite was considered as severe if graded 3 or 4 . When microbiological cultures were positive for a microorganism from the skin flora (except blood cultures positive for coagulase-negative staphylococci or Bacteroides sp.), clinical and laboratory data were analyzed to differentiate true infection from colonization.

Patients were managed by the physicians in charge according to the usual national and international guidelines. Administration of BothroFav antivenom was decided according to the recommendations. ${ }^{1,11}$ In our hospital, combinations of third-generation cephalosporin (or amoxicillinclavulanate), aminoglycoside, and metronidazole are routinely prescribed at admission to patients with grade 3-4 envenoming, and during stay, to patients with signs of infection regardless of the degree of envenoming.

Statistical analysis. Continuous variables are expressed as mean \pm SD. Categorical variables are expressed as number (percentage). Differences between groups were assessed using Student's $t$-tests for continuous variables and Chi-squared tests for categorical variables. Correlation between variables was determined using linear regression. Data were analyzed using the Excel (2007) and SPSS program version 24. $P$-values $<0.05$ were considered as significant.

\section{RESULTS}

During the 8-year study period, 170 patients (age: $45 \pm 18$ years, including seven children (4\%); male-to-female gender ratio of 2.5) were referred to our hospital for snakebite management (Table 2).

Incidence. The number of snakebites was 21 cases per year (Figure $1 \mathrm{~A})$, corresponding to an incidence rate of six bites per 100,000 inhabitants per year in Martinique. Monthly distribution of snakebites showed peak incidence in June, July, and September, with an average of two bites per month (Figure 1B and C). No significant relationship between the seasonal incidence of snakebite and precipitation registered by the French national meteorological service was observed (Figure 2A), whereas the number of snakebites significantly increased when the recorded maximal temperature was above $30^{\circ} \mathrm{C}\left(R^{2}=0.33\right.$; Figure $2 \mathrm{~B}$ and $\left.\mathrm{C}\right)$.

Presentation and post-snakebite infection onset. On hospital admission, 39 patients (23\%) presented with grade 3 or 4 envenoming. Twenty patients (12\%) had clinical signs suggestive of post-snakebite infections. Bacteriological samples were positive in seven cases (35\%). The isolated bacteria were $M$. morganii in two cases, $A$. hydrophila in three cases, Streptococcus A in one case, and Streptococcus B in one case. All isolated M. morganii and $A$. hydrophila were susceptible to third-generation cephalosporins. The main factor associated with the occurrence of infection following snakebite was the severity of the bite. Twelve patients (31\%) developed infection in the severely envenomed patients versus eight $(6 \%)$ in the non-severely envenomed patients $(P<$ 0.0001; Figure 3).

Management and outcome. Seventy-nine patients (46\%) were admitted to the medical ward, $25(15 \%)$ to the intensive care unit (ICU), and three (2\%) to the surgical ward, whereas $63(37 \%)$ were discharged after management in the emergency department. Almost all patients (93\%) were treated with the specific BothroFav antivenom. It is noteworthy that patients presenting infections more frequently required antivenom readministration than those without infection (53\% versus $7 \%, P<0.001$; Table 2 ). Based on the severity of the envenoming grade and the suspicion of local infection, 37 patients received one antibiotic or a combination of antibiotics. The following antibiotics were administered empirically: third-generation cephalosporin in 17 (10\%) patients, amoxicillin-clavulanate in 11 (6\%) patients, gentamycin in 12 (7\%) patients, and metronidazole in 12 (7\%) patients.

The complications observed during hospitalization are reported in Table 3. No myocardial infarction or brain stroke occurred. No patient died. Length of hospital stay was $3 \pm$ 5 days $(6 \pm 9$ days in the ICU versus $3 \pm 4$ days in the other hospital wards, $P=0.01)$. Length of hospital stay significantly increased according to the severity grade of the snakebite $\left(R^{2}=0.77\right.$; Figure 4$)$ and was significantly longer in patients with infection $(11 \pm 10$ versus $2 \pm 1$ days, $P<0.0001)$. 
A

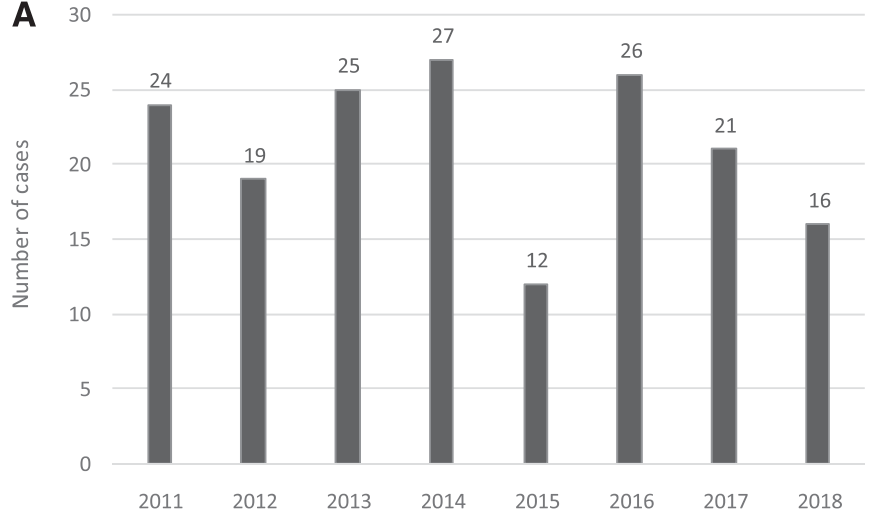

B

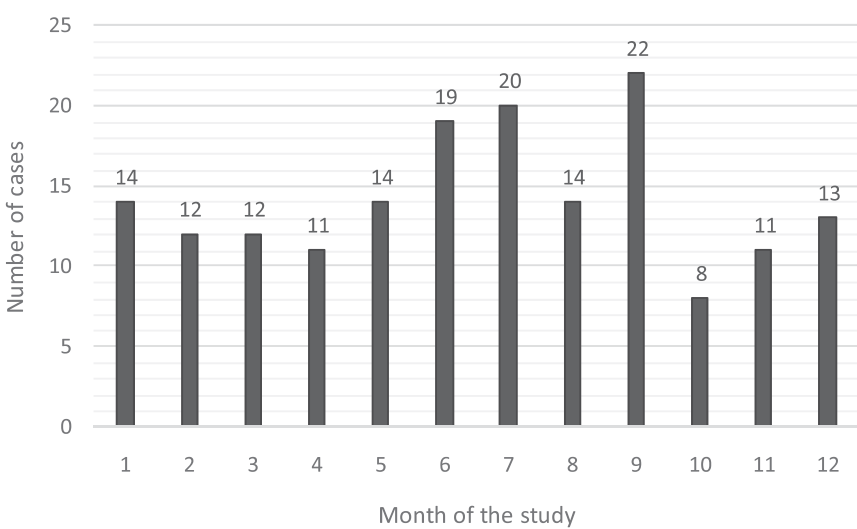

C

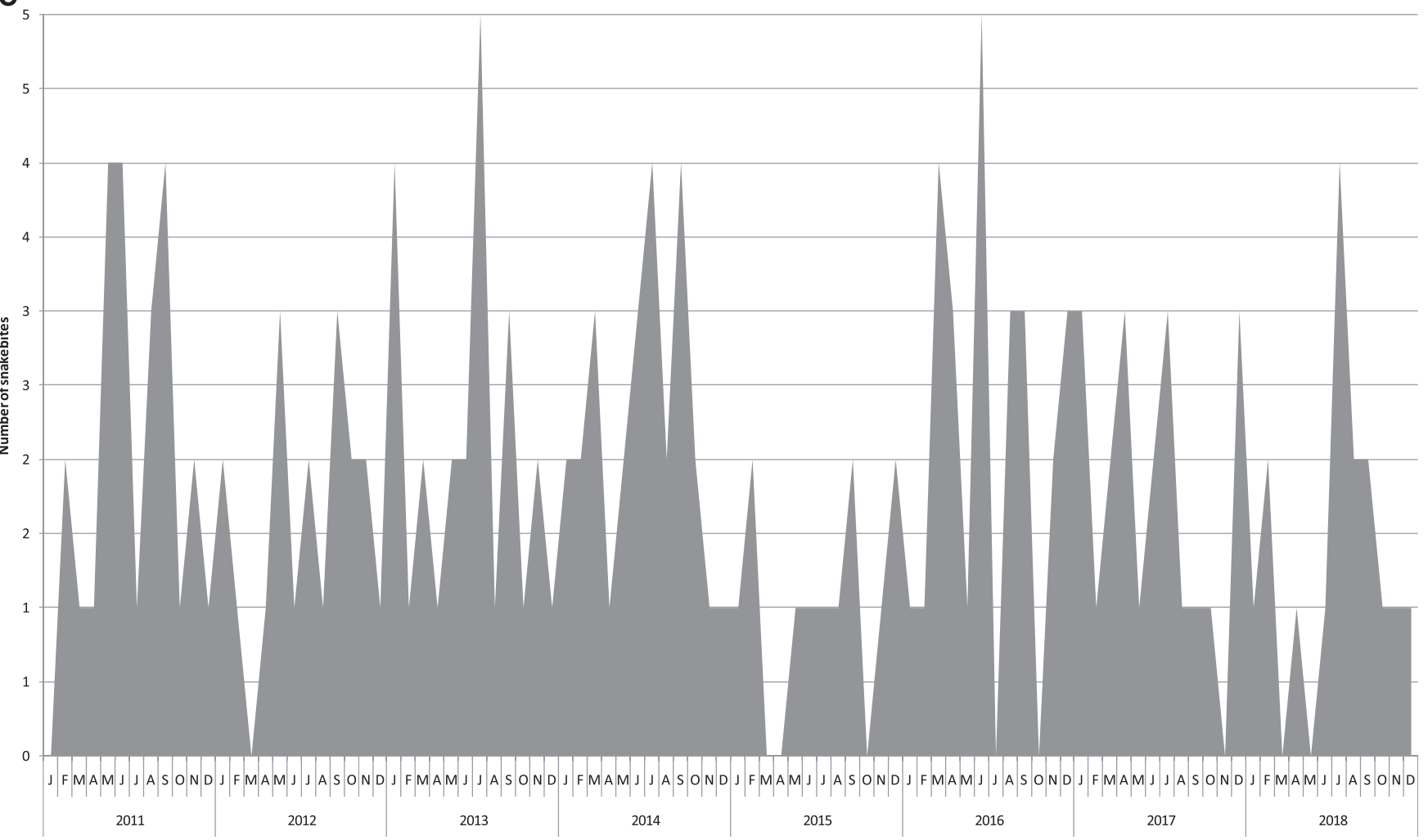

FIGURE 1. Distribution of the 170 Bothrops lanceolatus bite cases according to the year (A) and month (B and C) of the study.

\section{DISCUSSION}

Infection following $B$. lanceolatus bite is relatively frequent ( $12 \%$ in our case series), and patients at highest risk are those presenting with severe envenoming (grades 3 and 4). The bacteria responsible for wound infection are those commonly isolated from the snake mouth, suggesting that the main source of contamination comes from the snake causing the bite.

Wound infection following snakebite usually accounts for $9-77 \%$ of the bitten patients, as described in several studies (Table 4) ${ }^{5,6,8,12-15}$ The large differences in the reported prevalence of secondary infections in snakebites between different studies can be related to variations in the criteria used to establish the presence of infection. A strict criterion is the laboratory isolation and identification of bacteria from the affected tissues or blood in envenomed patients. However, clinical criteria are also used to diagnose infection. In this regard, discrepancies may arise because some clinical manifestations of local infection can also be caused by the action of venom toxins in the tissue, associated with inflammation. In our study, infection was defined as the presence of two of the following local signs: pain, erythema, local warmth, swelling, lymphangitis, purulence, delayed healing, crepitus in soft tissues, discolored or friable granulation tissue, and wound breakdown or dehiscence, or alternatively, the presence of fever and/or chills and at least one of these signs. ${ }^{8,9}$ Thereafter, in patients with local signs of infection, samples were obtained from local tissues, fluids, and blood and sent to the laboratory for bacterial culture and identification. In case of sterile microbiological cultures, the diagnosis of infection was assessed according to clinical and biological parameters. Indeed, initial antibiotic therapy can result in negative 

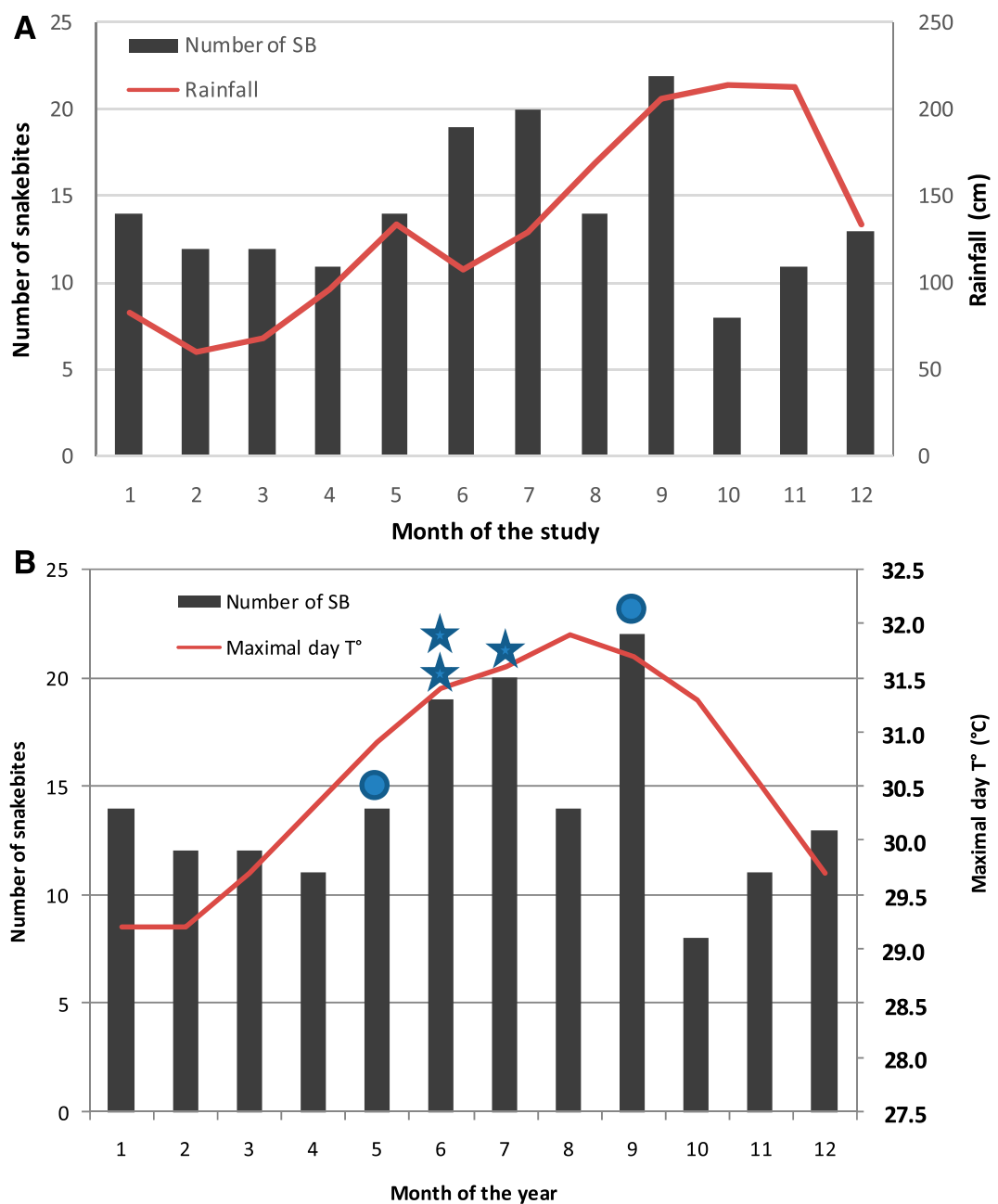

32.5

31.5

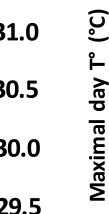

29.0

28.5

28.0

27.5

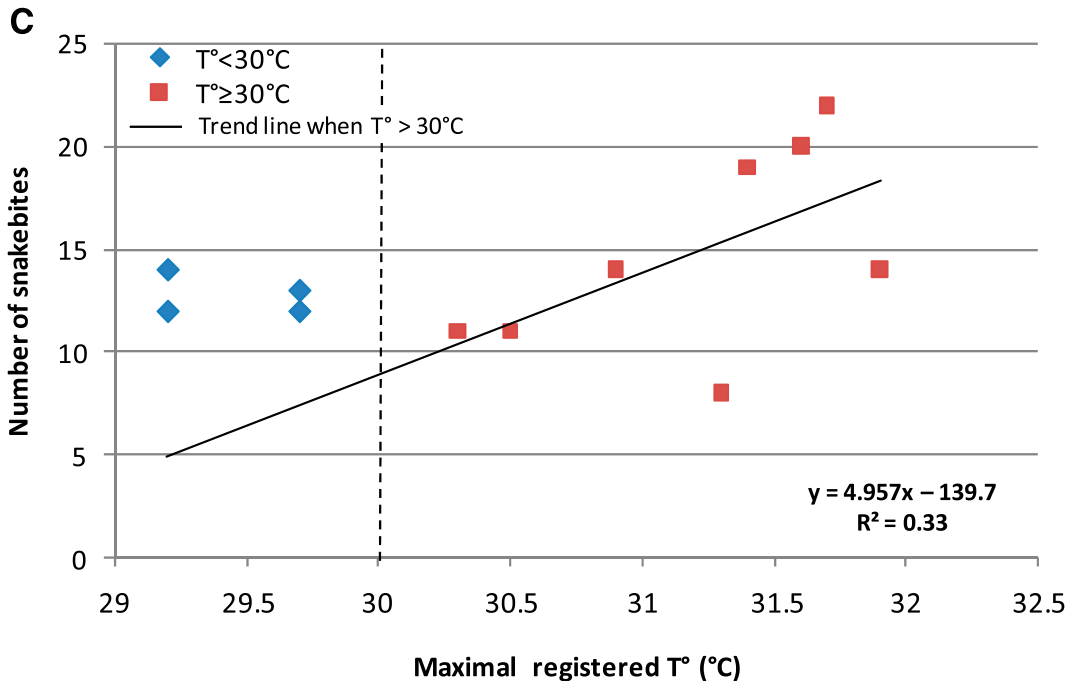

FIGURE 2. Relationship between the monthly distribution of Bothrops snakebites and the recorded rainfall (A) and maximal temperatures (B and C). The line shows the trend in snakebites when the recorded maximal temperature is above $30^{\circ} \mathrm{C}$. Stars represent cases with Aeromonas hydrophila infection and circles represent cases with Morganella morganii infection. This figure appears in color at www.ajtmh.org.

microbiological culture, and the prevalence of patients who developed wound infection secondary to snakebite could not be calculated as only those with positive microbiological cultures. ${ }^{16,17}$ Future studies should attempt to develop a more uniform set of criteria to define infection in snakebite envenomings to harmonize parameters that would allow comparison between studies.

The main involved bacteria are $A$. hydrophila (Gramnegative bacilli), recognized to cause soft tissue infections and necrotizing fasciitis. ${ }^{18}$ Aeromonas hydrophila is generally 


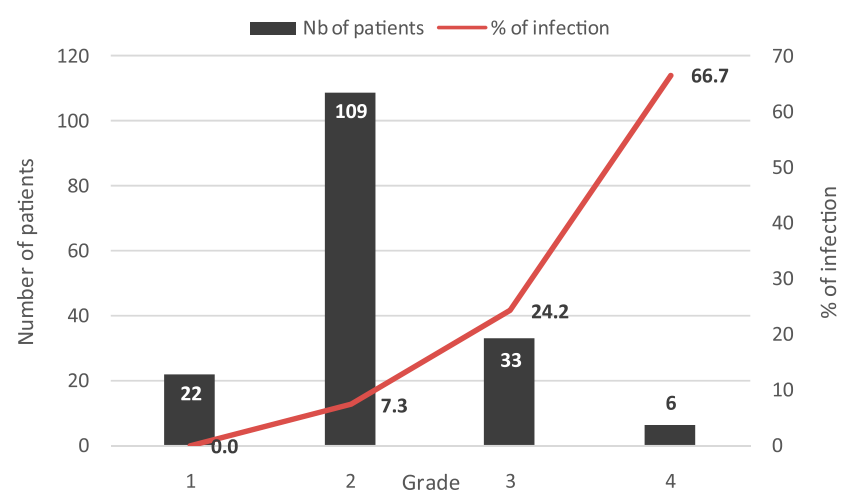

FIGURE 3. Prevalence of infection according to the grade of envenoming. This figure appears in color at www.ajtmh.org.

found in sewage, freshwater, stagnant water, and feces. Other bacteria such as $M$. morganii have also been isolated in abscesses after $B$. lanceolatus bite. They are also found in the mouth and on the fangs of these viperids. Staphylococci, group D streptococci, Clostridium, Escherichia coli, and Enterococcus faecalis, involved in wound infection, have been also isolated from the mouth of viperid species. ${ }^{19}$ Serratia marcescens is rarely isolated from cellulitis following snakebite but may be responsible for bullous cellulitis. By contrast, Staphylococcus aureus is not commonly isolated from the snake mouth, suggesting that if the organism causes postsnakebite infections, it probably originates from the patient's skin rather than having been inoculated by the snake fangs. Therefore, strict disinfection of the bite site should systematically be performed. ${ }^{14}$ The snake mouth is colonized by bacteria which can be transmitted to the bitten patient through the skin injury associated with the bite. ${ }^{7}$ Inoculation of bacteria from the mouth, fangs, or venom of $B$. lanceolatus following a bite can cause local infection with abscess and necrotizing fasciitis in the most severe cases, as described in other cases of snakebites. ${ }^{20}$ Based on the most frequently isolated bacteria in the snakebite site according to the literature (Table 4), active antibiotics include third-generation cephalosporins, piperacillin-tazobactam, and ciprofloxacin. Conformingly, in one recent study, isolated Enterobacteriaceae following snakebite infection showed $69 \%$ resistance to ampicillin, $60 \%$ resistance to amoxicillin-clavulanate, and $66 \%$ resistance to second-generation cephalosporins. ${ }^{20}$ By contrast, bacteria were sensitive to ceftriaxone in $97 \%$ of the cases and sensitive to ciprofloxacin and aminoglycosides in $100 \%$ of the cases. Enterococcus faecalis showed $92 \%$ sensitivity to ampicillin and amoxicillin-clavulanate and $100 \%$ sensitivity to ciprofloxacin. A recent experimental study examining the bacteria sampled

TABLE 3

Local signs recorded in 170 infected and noninfected Bothrops lanceolatus-bitten patients

\begin{tabular}{lccc}
\hline & $\begin{array}{c}\text { Total patients } \\
(N=170)\end{array}$ & $\begin{array}{c}\text { Infected patients } \\
(N=20)\end{array}$ & $\begin{array}{c}\text { Noninfected patients } \\
(N=150)\end{array}$ \\
\hline Increasing pain & $28(17 \%)$ & $20(100 \%)$ & $8(5 \%)$ \\
Abscess & $7(4 \%)$ & $7(35 \%)$ & 0 \\
Erythema & $17(10 \%)$ & $16(80 \%)$ & $1(1 \%)$ \\
Cellulitis & $4(2 \%)$ & $4(20 \%)$ & 0 \\
Necrosis & $5(3 \%)$ & $5(25 \%)$ & 0 \\
Necrotic fasciitis & $1(1 \%)$ & $1(5 \%)$ & 0 \\
Gangrene & 0 & 0 & 0 \\
\hline
\end{tabular}

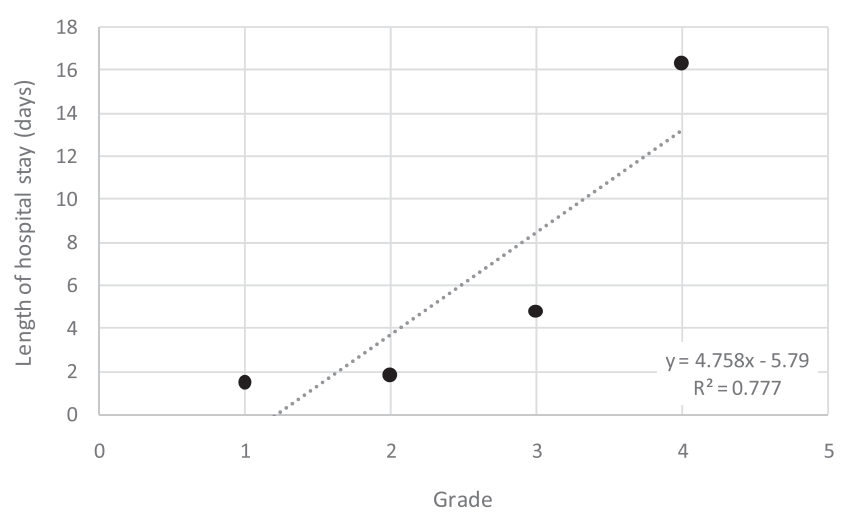

FIGURE 4. Length of hospital stay according to the grade of envenoming in 170 Bothrops lanceolatus-bitten patients.

from the oral cavity of $26 B$. lanceolatus specimens collected from various areas in Martinique supported that microbiota from $B$. lanceolatus oral cavity was polymicrobial. ${ }^{7}$ The most frequently isolated bacteria were A. hydrophila (present in $50 \%$ of the samples), M. morganii, K. pneumoniae, Bacillus spp., and Enterococcus spp. Analysis of antibiotic susceptibility revealed that $67 \%$ of the isolated bacteria were resistant to amoxicillinclavulanate. By contrast, most of the isolated bacteria were susceptible to third-generation cephalosporins (i.e., $73 \%$ to cefotaxime and $80 \%$ to ceftazidime). Similar data were also reported in the oral microbiota of snakes from Brazil and India. $^{19,21}$

Despite snake oral and fang contamination with a wide variety of pathogenic bacteria, envenoming can be seen as a process associated with relatively limited risk of bacterial infection, except in cases associated with prominent tissue damage at the site of venom injection. Antibacterial effects of snake venoms may limit the likelihood of infection. Bactericidal activity against Gram-positive and Gram-negative bacteria was attributed to various components, including L-amino acid oxidases and phospholipase A2 enzymes. ${ }^{22-27}$ However, these bactericidal effects are likely to decrease once the venom has been injected. Soft tissue infection occurs in patients suffering severe envenomings (grade 3 or 4 ) in which the injected venom amount is likely to be high. Therefore, it is suggested that venom-induced skin and muscle damage is favorable for bacterial colonization and constitutes the bed of infection, as has been shown in an experimental model in mice. $^{28}$

In the Practice Guidelines for the Diagnosis and Management of Skin and Soft Tissue Infections, ${ }^{29}$ use of antimicrobial agents active against both aerobic and anaerobic bacteria, such as amoxicillin-clavulanate, is recommended in bitten patients. However, the widespread systematic antibiotic administration is questionable after snakebite. Most authors recommend antibiotics in severely bitten patients, especially when local tissue damage occurs and inflammatory signs are suggestive of infection. Interestingly, empiric amoxicillinclavulanate use was shown to be ineffective in preventing secondary infections from Bothrops snakebites because of the resistance to $\beta$-lactam antibiotics in the bacterial species commonly found infecting the snakebite site. ${ }^{15}$ Recently, analysis of the antibiotic susceptibility of bacteria isolated from $B$. lanceolatus mouth showed $67 \%$ of strains resistant to amoxicillin-clavulanate, whereas most isolated bacteria were 
RESIERE AND OTHERS

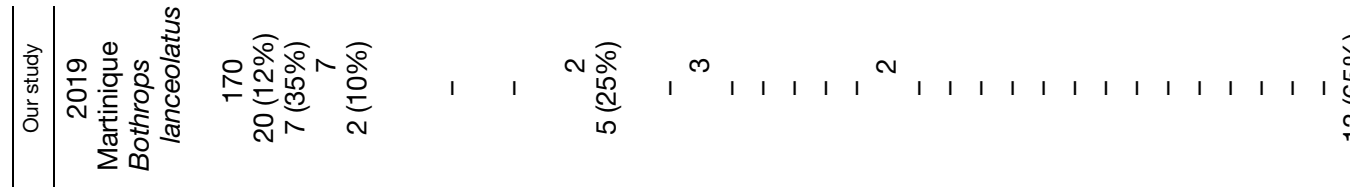

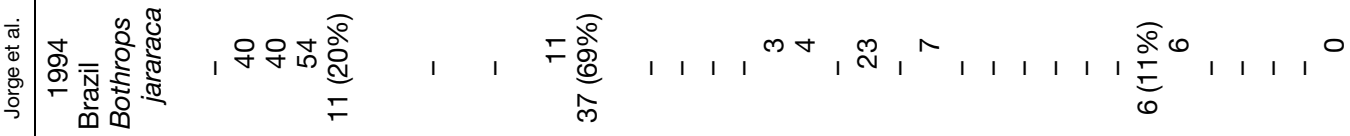

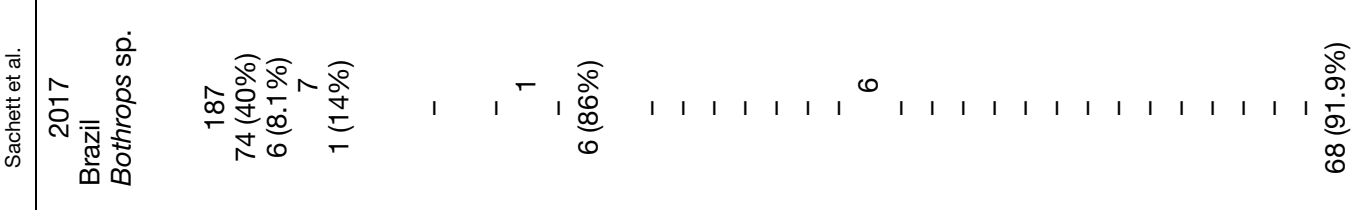

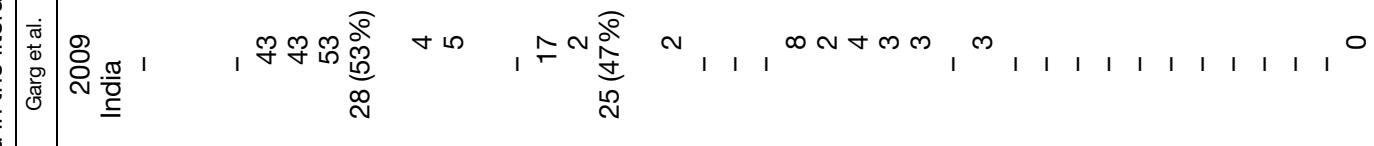

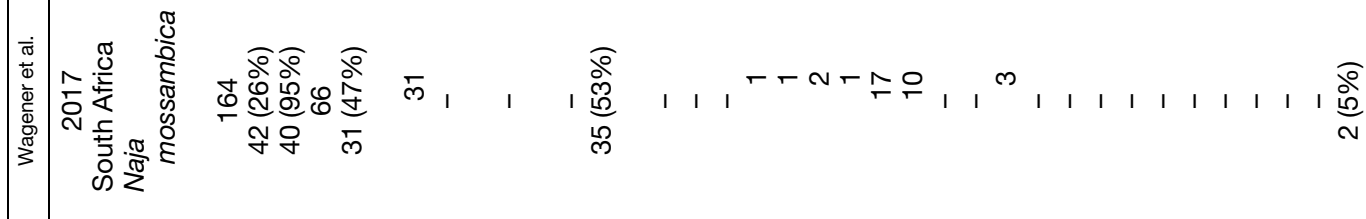

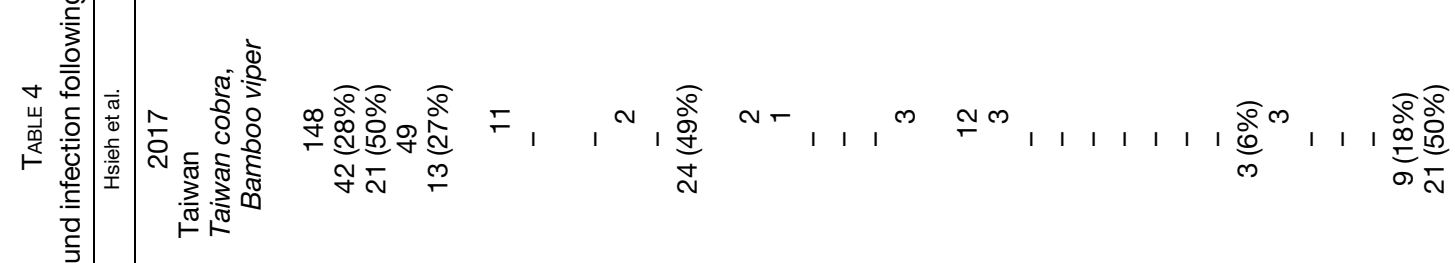

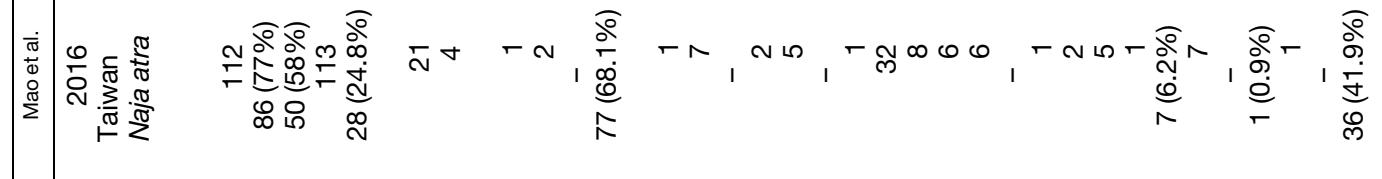

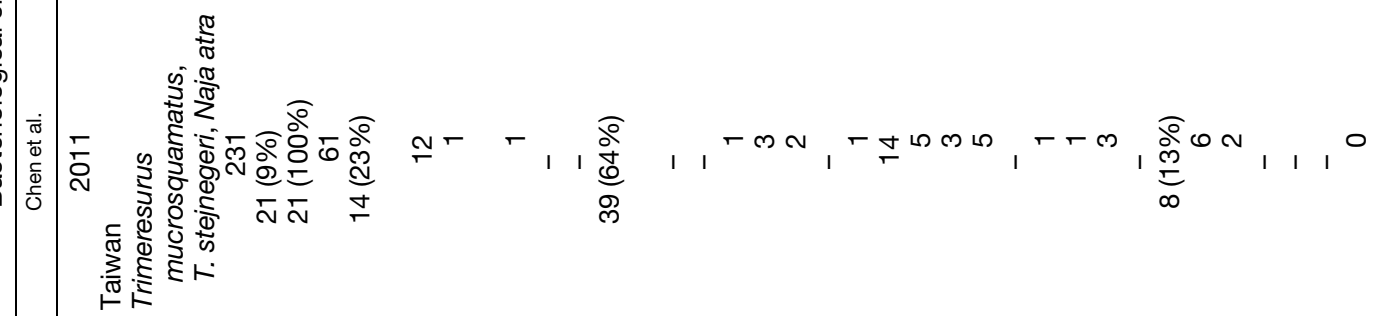

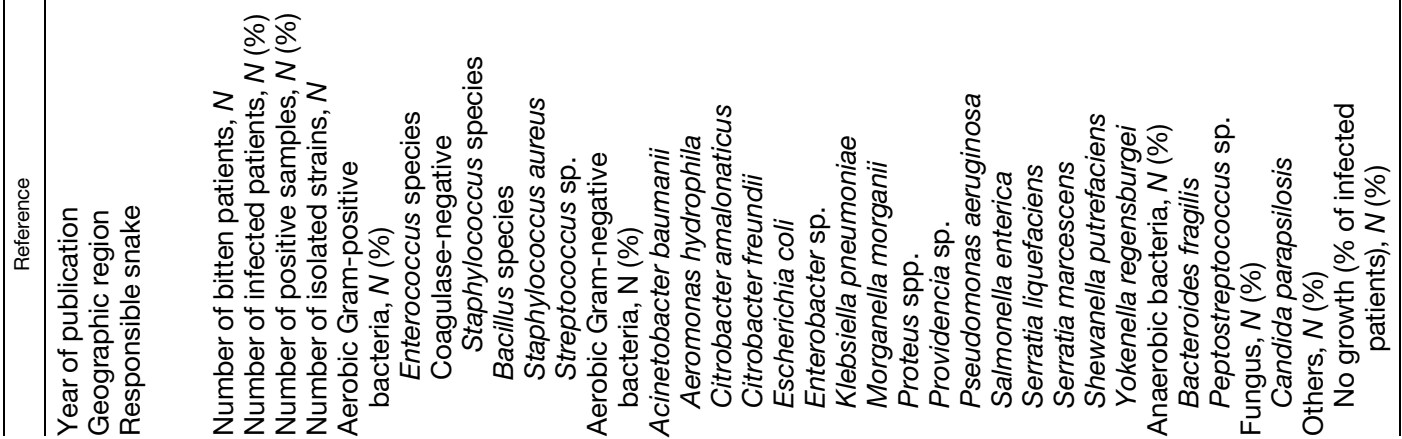


susceptible to third-generation cephalosporins. ${ }^{7}$ In our hospital, empiric cephalosporin (or amoxicillin-clavulanate), aminoglycoside, and metronidazole combinations are routinely used in grade 3 or 4 envenoming and in case of clinical evidence of infection. Ciprofloxacin is the antibiotic of choice in case of allergy to $\beta$-lactams. This antibiotic treatment strategy probably explains the low prevalence of positive cultures (only 35\%) from our patients' samples in comparison to other reports in the literature (Table 4). However, we do not support the systematic antibiotic administration in all snake-bitten patients to reduce the risk of infection because such prophylactic use (including in non-severely envenomed patients) may have little impact on further infection but may give rise to side effects and select resistant organisms. Antibiotic administration should be considered only in patients having prominent local tissue damage and inflammation.

Our study has limitations. The diagnosis of wound infection involves repeated clinical assessment, biological dosing, and microbiological cultures. The involved bacteria were only identified in a limited number of cases having clinical evidence of infection possibly because of the difficulties of wound sampling in the emergency department and the fact that sample collection was performed after the antibiotic administration in some cases. This diagnostic approach is approved by many authors working on the diagnosis of wound infection and how to differentiate true infection from colonization. ${ }^{8,9,16,17}$ Further studies are needed to assess the sensitivity and specificity of clinical and biological parameters to assess the diagnosis of wound infection following snakebite independently of the microbiological results. In our study, anaerobic bacteria were not identified, although they are reported to be one of the responsible microorganisms causing cellulitis following snakebite. This is explained by the lack of bacteriological media for the isolation of anaerobic bacteria in our work. Our retrospective study methodology also limited further analysis. In addition, no clear indications and determined regimen of antibiotics were available, and treatment was only based on the judgment of the physicians in charge of the patients.

In conclusion, wound infection following $B$. lanceolatus bite is relatively frequent in grade 3 and 4 envenomed patients. The main involved bacteria are $A$. hydrophila and $M$. morganii. The empirical scheme for antibiotics adapted to the bacterial ecology of $B$. lanceolatus oral cavity are recommended for at least patients with grade 3 and 4 envenoming or having signs suggestive of local infection, regardless of the degree of envenoming. Our data support that the most appropriate empirical antibiotics are third-generation cephalosporins and that empirical amoxicillin-clavulanate should no longer be used in this context.

Received May 13, 2019. Accepted for publication July 12, 2019.

Published online October 14, 2019.

\section{Acknowledgment: ANR generique Mitobothrops R. N. 2018}

Authors' addresses: Dabor Resiere, Hossein Mehdaoui, Adeline Beaudoin, Jonathan Florentin, Yannick Brouste, and Rishika Banydeen, Department of Critical Care, University Hospital of Martinique, Fort-de-France, France, E-mails: dabor.resiere@chu-martinique. fr, hossein.mehdaoui@chu-martinique.fr, adelinebeaudoin@gmail.com, jonathan.florentin@chu-martinique.fr, yannick.brouste@chu-martinique. fr, and rishika.banydeen@chu-martinique.fr. Rémi Névière, Department of Cardiology, University Hospital of Martinique, Fort-de-France, France, E-mail: remi.neviere@chu-martinique.fr. Claude Olive, Department of Microbiology, University Hospital of Martinique, Fort-de-France, France, E-mail: claude.olive@chu-martinique.fr. Mathieu Severyns, Department of Orthopedic Surgery, University Hospital of Martinique, Fort-deFrance, France, E-mail: mathieu.severyns@chu-martinique.fr. André Cabié, Department of Infectious Diseases, University Hospital of Martinique, Antilles University, Fort-de-France, France, E-mail: andre.cabie@ chu-martinique.fr. Bruno Mégarbane, Department of Medical and Toxicological Critical Care, Lariboisière Hospital, Paris-Diderot University, Paris, France, E-mail: bruno.megabarne@aphp.fr. José María Gutiérrez, Instituto Clodomiro Picado, Facultad de Microbiología, Universidad de Costa Rica, San José, Costa Rica, E-mail: jose.gutierrez@ucr.ac.cr. Hatem Kallel, Intensive Care Unit, Cayenne General Hospital, Cayenne, France, E-mail: hatem.kallel@ch-cayenne.fr.

This is an open-access article distributed under the terms of the Creative Commons Attribution License, which permits unrestricted use, distribution, and reproduction in any medium, provided the original author and source are credited.

\section{REFERENCES}

1. Gutiérrez JM, Calvete JJ, Habib AG, Harrison RA, Williams DJ, Warrell DA, 2017. Snakebite envenoming. Nat Rev Dis Primers 3: 17063.

2. Resiere D, Hossein M, Megarbane B, 2018. Snake bites by Bothrops lanceolatus in Martinique. Med Sante Trop 28: 37-43.

3. Thomas L, Chausson N, Uzan J, Kaidomar S, Vignes R, Plumelle Y, Bucher B, Smadja D, 2006. Thrombotic stroke following snake bites by the "Fer-de-Lance" Bothrops lanceolatus in Martinique despite antivenom treatment: a report of three recent cases. Toxicon 48: 23-28.

4. Thomas $L$ et al., 1998. Prognostic significance of clinical grading of patients envenomed by Bothrops lanceolatus in Martinique. Trans R Soc Trop Med Hyg 92: 542-545.

5. Garg A, Sujatha S, Garg J, Acharya NS, Chandra Parija S, 2009. Wound infections secondary to snakebite. J Infect Dev Ctries 3: 221-223.

6. Wagener M, Naidoo M, Aldous C, 2017. Wound infection secondary to snakebite. S Afr Med J 107: 315.

7. Résière $D$, Olive $C$, Kallel $H$, Cabié $A$, Névière R, Mégarbane $B$, Gutiérrez JM, Mehdaoui H, 2018. Oral microbiota of the snake Bothrops lanceolatus in Martinique. Int $J$ Environ Res Public Health 15: E2122.

8. Mao YC, Liu PY, Hung DZ, Lai WC, Huang ST, Hung YM, Yang CC, 2016. Bacteriology of Naja atra snakebite wound and its implications for antibiotic therapy. Am J Trop Med Hyg 94: 1129-1135.

9. Huang LW, Wang JD, Huang JA, Hu SY, Wang LM, Tsan YT, 2012. Wound infections secondary to snakebite in central Taiwan. J. Venom Anim Toxins Incl Trop Dis 18: 272-276.

10. Soussy $\mathrm{CJ}$ et al., 2000. Antibiogram committee of the French Microbiology Society. Report 2000-2001. Pathol Biol (Paris) 48: 832-871.

11. Resiere D, Mégarbane B, Valentino R, Mehdaoui $H$, Thomas $L$, 2010. Bothrops lanceolatus bites: guidelines for severity assessment and emergent management. Toxins (Basel) 2: 163-173.

12. Chen CM, Wu KG, Chen CJ, Wang CM, 2011. Bacterial infection in association with snakebite: a 10-year experience in a Northern Taiwan medical center. J Microbiol Immunol Infect 44: 456-460.

13. Hsieh YH, Hsueh JH, Liu WC, Yang KC, Hsu KC, Lin CT, Ho YY, Chen LW, 2017. Contributing factors for complications and outcomes in patients with snakebite: experience in a medical center in southern Taiwan. Ann Plast Surg 78 (3 Suppl 2): S31-S36.

14. Jorge MT, Ribeiro LA, Da Silva MLR, Kusano EJU, de Mendonça JS, 1994. Microbiological studies of abscesses complicating Bothrops snakebite in humans: a prospective study. Toxicon 32: 743-748.

15. Sachett JAG et al., 2017. Poor efficacy of preemptive amoxicillin clavulanate for preventing secondary infection from Bothrops 
snakebites in the Brazilian Amazon: a randomized controlled clinical trial. PLoS Negl Trop Dis 11: e0005745.

16. Ki V, Rotstein C, 2008. Bacterial skin and soft tissue infections in adults: a review of their epidemiology, pathogenesis, diagnosis, treatment and site of care. Can J Infect Dis Med Microbiol 19: 173-184.

17. Cefalu JE, Barrier KM, Davis AH, 2017. Wound infections in critical care. Crit Care Nurs Clin North Am 29: 81-96.

18. Gold WL, Salit IE, 1993. Aeromonas hydrophila infections of skin and soft tissue: report of 11 cases and review. Clin Infect Dis 16: 69-74.

19. Jorge MT, de Mendonça JS, Ribeiro LA, da Silva ML, Kusano EJ, Cordeiro CL, 1990. Bacterial flora of the oral cavity, fangs and venom of Bothrops jararaca: possible source of infection at the local bite. Rev Inst Med Trop Sao Paulo 32: 6-10.

20. Lam KK et al., 2011. A cross-sectional survey of snake oral bacterial flora from Hong Kong, SAR, China. Emerg Med J 28: 107-114.

21. Shaikh IK, Dixit PP, Pawade BS, Potnis-Lele M, Kurhe BP, 2017. Assessment of cultivable oral bacterial flora from important venomous snakes of India and their antibiotic susceptibilities. Curr Microbiol 74: 1278-1286.

22. Al-Asmari AK, Abbasmanthiri R, Abdo Osman NM, Siddiqui $Y, A l-$ Bannah FA, Al-Rawi AM, Al-Asmari SA, 2015. Assessment of the antimicrobial activity of few Saudi Arabian snake venoms. Open Microbiol J 9: 18-25.

23. Bustillo S, Leiva LC, Acosta O, Bal de Kier Joffé E, Gorodner JO, 2008. Antimicrobial activity of Bothrops alternatus venom from the northeast of Argentine. Rev Latinoam Microbiol 50: 79-82.
24. Hakim Md, Reza M, 2015. In vitro antibacterial activity of snake venom, Naja naja from Bangladesh. Br Biotechnol J 8: 1-5.

25. Nascimento Canhas I, Dias Heneine LG, Fraga T, Sampaio de Assis DC, Borges MH, Chartone-Souza E, Amaral Nascimento AM, 2017. Antibacterial activity of different types of snake venom from the Viperidae family against Staphylococcus aureus. Acta Scientiarum Biol Sci 39: 309-319.

26. Perumal Samy R, Gopalakrishnakone $P$, Thwin MM, Chow TKV, Bow H, Yap EH, Thong TWJ, 2007. Antibacterial activity of snake, scorpion and bee venoms: a comparison with purified venom phospholipase A2 enzymes. J Appl Microbiol 102: 650-659.

27. Santamaría C, Larios S, Angulo Y, Pizarro-Cerda J, Gorvel J-P, Moreno E, Lomonte B, 2005. Antimicrobial activity of myotoxic phospholipases A2 from crotalid snake venoms and synthetic peptide variants derived from their $\mathrm{C}$-terminal region. Toxicon 45: 807-815.

28. Saravia-Otten P, Gutierrez JM, Arvidson S, Thelestam M, Flock JI, 2007. Increased infectivity of Staphylococcus aureus in an experimental model of snake venom-induced tissue damage. $J$ Infect Dis 196: 748-754.

29. Stevens DL, Bisno AL, Chambers HF, Dellinger EP, Goldstein EJC, Gorbach SL, Hirschmann JV, Kaplan SL, Montoya JG, Wade JC, 2014. Practice guidelines for the diagnosis and management of skin and soft tissue infections: 2014 update by the Infectious Diseases Society of America. Clin Infect Dis 59: 147-159. 